\section{RELAÇÕES DE GÊNERO NO ESPORTE: "O BELO SEXO" NA COMPETIÇÃO DE NATAÇÃO EM MAR ABERTO - TRAVESSIA MAR GRANDE-SALVADOR, BAHIA, BRASIL}

\author{
GENDER RELATIONS IN SPORTS: THE "BEAUTIFUL SEX" IN THE MAR \\ GRANDE-SALVADOR OPEN SEA SWIMMING COMPETITION IN BAHIA, BRAZIL \\ RELACIONES DE GÉNERO EN EL DEPORTE: EL "BELO SEXO" EN LA \\ COMPETICIÓN DE NATACIÓN EN MAR ABIERTO -TRAVESSIA MAR GRANDE- \\ SALVADOR, BAHIA, BRASIL
}

Lygia Maria dos Santos Bahia*, Maria Cecília de Paula Silva*

\begin{abstract}
Palavras chave: Educação.

Mulheres.

Natação.

História.

Esportes

Resumo: 0 artigo objetiva discutira educação de mulheres no esporte, com destaque para as representações e papéis sociais que lhes são tradicionalmente concedidos, a partir da participação na Travessia Mar Grande-Salvador, Bahia, Brasil, prova de natação em mar aberto na Baía de Todos os Santos. Pesquisa histórica, que privilegia a História Oral temática e fontes documentais. A análise de conteúdo nos permitiu interpretar os sentidos produzidos. Dos resultados encontrados apontamos que desde 1956 (quando se inicia essa competição esportiva) até os dias atuais as participantes são mulheres da elite soteropolitana, escolarizadas. Apesar dos avanços, as resistências à prática esportiva em mar aberto permanecem. Concluímos que a participação das mulheres nessa prova contribuiu e contribui para romper velhos padrões, a exemplo da educação que sugere papéis diferenciados e submissos para as mulheres, mudando lógicas de dominação e abrindo novos caminhos.
\end{abstract}

Keywords:

Education.

Women.

Swimming.

History.

Sports.

Palabras clave:

Educación

Natación.

Mujeres.

Historia.

Deportes.

\begin{abstract}
The article aims to discuss women's education in sports, focusing on social representations and roles traditionally ascribed to them, starting from the participation in the Mar Grande-Salvador Crossing, in Bahia, Brazil - an open sea swimming competition in the Todos os Santos Bay. This is a historical research focused on thematic oral history and documentary sources. Content analysis allowed us to interpret meanings. The results found include the fact that participants were educated women from Salvador's elite since 1956 (when that competition started). Despite the advances, resistance remains to open sea swimming. We conclude that women's participation in that competition contributed to break old patterns such as education that suggests distinct and submissive roles for women, changing the logic of domination and opening up new paths.
\end{abstract}

Resumen: El artículo objetiva discutir la educación de mujeres en el deporte, con destaque para las representaciones y papeles sociales que le son tradicionalmente concedidos, a partir de la participación en la Travessia Mar Grande-Salvador, Bahia, Brasil, prueba de natación en mar abierto en la Bahía de Todos los Santos. Investigación histórica, que privilegia la historia oral temática y fuentes documentales. El análisis de contenido nos permitió interpretar los sentidos producidos. De los resultados encontrados apuntamos que desde 1956 (cuando se inicia esta competición deportiva) hasta los días actuales las participantes son mujeres de la elite soteropolita, escolarizadas. A pesar de los avances, las resistencias a la práctica deportiva en mar abierto, permanecen. Concluimos que la participación de las mujeres en esta prueba contribuyó a romper viejos patrones, a ejemplo de la educación que sugiere papeles diferenciados y sumisos para las mujeres, cambiando lógicas de dominación, y apertura de nuevos caminos.
*Universidade Federal da Bahia. Salvador, BA, Brasil. E-mail: lygia.bahia@ hotmail.com; cecilipaula@gmail.com

Recebido em: 21-11-2017 Aprovado em: 12-04-2018

DOI: http://dx.doi.org/10.22456/1982-8918.78174 (c) (1) (8) Licence 


\section{INTRODUÇÃO}

A história da educação das mulheres no Brasil tem sido marcada por um longo processo de lutas contra as restrições que thes foram impostas nos diferentes períodos históricos do país. Herdeira de uma educação medieva europeia, a educação no Brasil se consolidou na estrutura patriarcal, em que o homem exercia pleno poder. Neste contexto, para Scott (2013), a educação das mulheres prezava a subalternidade, a obediência e a submissão ao homem. Pinsky (2013b) argumenta que a vida, para as mulheres, era restrita ao ambiente doméstico e tinha no casamento, na maternidade e nas tarefas domésticas o principal propósito. Em relação ao conhecimento das letras, Hahner (2013) afirma ser muito restrito na sua educação e, quando presente, limitava-se às mulheres da elite.

Esse modelo fortemente incorporado na cultura brasileira permanece como uma marca na educação das mulheres, mesmo quando os novos ares de modernidade bafejam sobre 0 Brasil do século XX. Paralelamente a essa educação conservadora elas iniciam um processo de lutas para adquirir autonomia e acesso a outros espaços sociais, dentre eles, o esportivo.

A ideia de adequação do esporte à biologia e função social das mulheres favoreceu a prática de esportes como a natação. Autores como Devide (2004) e Miguel e Rial (2013) entendem que o pioneirismo de ser um dos primeiros esportes competitivos praticados por mulheres se respaldava na concepção de que era benéfica para a função reprodutora e por não alterar as formas femininas e a graciosidade. Para Miguel e Rial (2013, p. 159), "[...] não é coincidência que a primeira participação de uma brasileira (e sul-americana) em uma Olimpíada (a de Los Angeles em 1932) tenha sido de uma nadadora".

$\mathrm{Na}$ década de 1950, período em que iniciam as primeiras participações de mulheres na Travessia a nado Mar Grande-Salvador, a educação das mulheres no Brasil valorizava características tradicionalmente definidas para elas, tais como: feminilidade, delicadeza, doçura, como também papéis sociais como a maternidade, o cuidado da família e das tarefas domésticas.

Apesar da saída para o espaço público, em parte provocada pelas mudanças sociais, políticas e econômicas do período, as mulheres foram enquadradas num modelo de conduta "ideal" para a sociedade em transformação. Pinsky (2013b, p. 470) afirma que "na primeira metade do século XX, parecia não haver dúvidas de que a mulher era, 'por natureza', destinada ao casamento e à maternidade".

A Travessia Mar Grande-Salvador, evento esportivo escolhido para discutir a educação das mulheres, é uma competição em mar aberto, de aproximadamente $10 \mathrm{~km}$, cujo local de saída é a praia do Duro, distrito de Mar Grande, município de Vera Cruz, e chegada na praia do Porto da Barra, em Salvador. Tem a peculiaridade de iniciar na ilha de Itaparica, atravessar a Baía de Todos os Santos e terminar em Salvador. A prova tem início em1955, e em 10 de janeiro de 2016 completou a 52ª edição. A participação feminina começa a partir de 1956.

Ao longo dos 60 anos, desde as primeiras participações das mulheres na travessia até a última edição, em 2016, a educação das mulheres no Brasil vivenciou um intenso processo de emancipação/resistência, a fim de conquistar direitos em todos os setores da sociedade nos esportes. Apesar dos avanços, permanecem, mesmo que velados, preconceitos e resistências sociais à participação das mulheres nesse evento em mar aberto. A partir desse contexto, 
objetivamos discutir a educação das mulheres no esporte, com destaque para as representações e papéis sociais que Ihes são tradicionalmente concedidos, a partir da participação na Travessia Mar Grande-Salvador.

Privilegiamos a metodologia da História Oral temática, que se caracteriza por ser um meio, um caminho, para a produção do conhecimento histórico (DELGADO, 2006). Alberti (2005, p. 155) a identifica como aquela que "consiste na realização de entrevistas gravadas com indivíduos que participaram de, ou testemunharam, acontecimentos e conjunturas do passado e do presente". Optamos pela entrevista temática, que transforma objetos de estudo em sujeitos e "contribui para uma história que não é só mais rica, mais viva e mais comovente, mas também mais verdadeira" (THOMPSON, 1992, p.137).

Meihy (2005) considera que a escolha dos depoentes deve ser baseada no papel social do colaborador, evitando-se depoimentos não essenciais para a pesquisa. Consideramos as entrevistas como sendo uma leitura individual e coletiva já que expressam a autoconsciência dos sujeitos participantes em períodos distintos.

Quatro mulheres ${ }^{1}$ e dois homens ${ }^{2}$ foram entrevistados por considerarmos suas informações suficientes no fornecimento de elementos importantes para o estudo, em acordo com Delgado (2006). Duas nadadoras das primeiras provas com participação feminina (1956 e 1957) e duas nadadoras da última travessia (2016). Os outros entrevistados estiveram envolvidos em edições da travessia em diversas funções, como, por exemplo, organizador, árbitro e/ou técnico. Os contatos foram realizados por meio de catálogo telefônico, redes sociais e pessoas envolvidas na competição.

Das fontes documentais primárias destacamos o jornal $A$ Tarde, periódico que participa da organização e divulgação da Travessia desde sua primeira edição, e o Diario de Noticias. Utilizamos também artigos e livros. Escolhemos a análise de conteúdo proposta por Véron (1980) para a interpretação do material. O autor considera que toda a produção do sentido depende do social, sendo impensável imaginar qualquer fenômeno de sentido apartado da cultura. Isso nos leva a considerar o contexto histórico, social e cultural em que o fenômeno é produzido como importante na compreensão dos sentidos e significados.

\section{A EDUCAÇÃO DAS MULHERES NO BRASIL - UM POUCO DE HISTÓRIA}

Conhecer a história da educação das mulheres no Brasil nos permite compreender como foi a trajetória para a conquista de espaços nunca pensados para elas. A história da educação das mulheres confunde-se com sua própria história. Para elas tem sido relegado um papel subalterno, invisível, confinado a um silêncio, a uma quase não existência, como se não fizessem parte dos acontecimentos, dos relatos, das experiências humanas, enfim, da história. "A segregação social e política a que as mulheres foram historicamente conduzidas tivera como consequência a sua ampla invisibilidade como sujeito [...]" (LOURO, 1997, p. 17).

Esse descaso relativo à vida das mulheres é resultante de um processo educativo excludente, subserviente, ao qual historicamente, em muitas civilizações, foi submetida. 0 acesso ao saber tem se constituído de lutas e batalhas como em quase tudo o que diz respeito a seus direitos. Por muito tempo, os saberes que lhes eram autorizados se restringiam àqueles

1 Angela Maria Carvalho; Desirée Dalia ; Fernanda Silva Scher; Marília Barreiros Correia de Melo. 
ensinados pelas mães e mulheres do seu convívio. Coser, lavar, cozinhar, cuidar da casa e da família; esse era o conhecimento necessário à sua existência. $O$ saber da leitura, da escrita, da boa conversação, dos conhecimentos sobre a vida e o mundo era considerado antagônico à sua natureza, ao seu papel social.

O Brasil colonial, cuja estrutura econômica nascente foi fundada na grande propriedade e na mão de obra escrava, favoreceu o nascimento da família patriarcal. Nessa organização familiar não cabia às mulheres o conhecimento das letras, da educação (ROMANELLI, 1995). O enfrentamento, as resistências e as poucas disposições sociais para que o quadro se revertesse não conseguiram dissolver facilmente as inúmeras barreiras erguidas.

Após a República, o discurso sobre a necessidade do país se modernizar e sair do estado secular de analfabetismo e ignorância permeou as discussões em vários setores da sociedade. Nessa época, a educação formal feminina da elite brasileira era bastante incipiente. A educação das meninas tinha como objetivo principal prepará-las para atividades domésticas necessárias para a futura mãe e dona de casa.

A chegada do século XX não provocou rupturas nem modificações expressivas no que se refere à sua educação. Segundo Silva (1998), as diferenças relativas ao gênero, no início desse século, eram acentuadas. Se para os homens a educação preparava para a vida pública, para as mulheres era restrita, preparando-as para o setor privado, ou seja, sua casa, marido e filhos.

Nos anos 1950 o Brasil mudou em vários aspectos devido à crescente industrialização, urbanização e modernização das cidades. Os espaços da cidade se modificaram gerando novos hábitos, como o de frequentar lojas, bares, escolas, dentre outros. Nesse cenário as mulheres ganharam alguma autonomia para usufruir da liberdade de ir e vir. A escolaridade feminina aumentou significativamente e novas conquistas foram alcançadas, como 0 direito à educação formal.

Porém, a trajetória escolar e profissional das mulheres era de menor prestígio e remuneração do que a dos rapazes. Na maioria dos casos, o magistério primário era a opção, já que se associava à missão das mulheres no lar (PINSKY, 2013b). A escolha do magistério se apoiava na sua característica formadora, cuidadora e abnegada, com afinidade à "natureza das mulheres", além de não representar um perigo maior na ordem social instituída, pois "[...] era um trabalho de um 'só turno', o que permitia que elas atendessem suas 'obrigações domésticas' no outro período" (LOURO, 2015, p.453).

Apesar do incremento das possibilidades à educação e ao trabalho para ambos os sexos, as distinções entre os papéis dos homens e das mulheres ainda eram marcantes. Para Pinsky (2013b), do começo do século XX até o início dos anos 1960, se firmam modelos de feminilidade. Mesmo que assumindo diferentes contornos, a educação das mulheres nos anos 1950 preservava características feminis, ao tempo em que agregava novas conquistas e liberdades. 0 recato, a docilidade, a obediência aos pais, a preservação da virgindade, a valorização da "moça de família", o casamento por amor, a boa esposa, a divisão dos papéis masculinos e femininos representavam o universo das mulheres, portanto faziam parte da sua educação.

Ao longo dos séculos XX eXXI, avanços e conquistas como a libertação da sexualidade, o controle da maternidade, a instituição do divórcio, o acesso crescente ao campo educacional e profissional permitiram que as mulheres exercessem outros papéis sociais, além daqueles 
relacionados ao ambiente doméstico. A família, a escola e a sociedade precisaram se modificar e atualizar condutas e expectativas em relação a elas.

Scott (2013, p. 25), baseada no Censo 2010, diz que "[...] as brasileiras têm um rendimento médio cerca de 30\% menor que o dos seus conterrâneos". Podemos afirmar que, em pleno século XXI, apesar de as mulheres estarem mais escolarizadas do que os homens e estudarem mais, elas ganham menos. Apesar do considerável aumento da escolarização das mulheres e do crescente acesso ao mercado de trabalho, permanece a desigualdade entre homens e mulheres.

Outra questão que tem sido alvo de debates é a distribuição das atividades domésticas, historicamente naturalizadas como "coisas de mulher". Com a crescente industrialização do país ao longo dos séculos XX e XXI e a necessidade de suprir as demandas do mercado, novas frentes de trabalho surgiram e permitiram, cada vez mais, que as mulheres assumissem uma ocupação fora do ambiente doméstico (SCOTT, 2013). Disso resultou um aumento considerável de responsabilidades, pois, para além das atividades profissionais, permanecem as de natureza doméstica. Essa "dupla jornada" de trabalho indica que ainda estamos longe de conseguir uma paridade entre suas responsabilidades sociais e a dos homens.

Concretizar outras aspirações tem sido muito difícil para as mulheres, a começar pelo ideário de "mãe abnegada", arraigado por uma educação conservadora. Muitas vezes ela se coloca em segundo plano diante das necessidades da família. Choca-se, portanto, a mulher moderna com a mãe. Ao tentar equilibrar trabalho e maternidade, Pinsky (2013a) argumenta que são criadas angústias pessoais, além dos agravos resultantes da sobrecarga de trabalho e discussões domésticas. Temos ainda uma longa travessia a percorrer.

\section{DE TRAVESSIAS - ENTRE A EDUCAÇÃO E O MAR ABERTO}

Falar de travessias nos remete a muitas chegadas e pontos de partida. Discutir a educação das mulheres a partir do campo esportivo nos permite identificar parte do processo histórico dessa educação. $O$ acesso ao campo das atividades físico-esportivas exemplifica uma das muitas "travessias" realizadas pelas mulheres, sendo, portanto, um dos espaços sociais que se abriu para elas, por conquista ou por concessão.

É a partir das primeiras décadas do século XX que o exercício físico começa a ser valorizado na educação brasileira. Isso decorre do Movimento Higienista, que se instalou no Brasil desde o século XIX, e principalmente no primeiro governo de Getulio Vargas, e que ganhou força e poder político (GÓIS JUNIOR; SIMÕES, 2011). O discurso desse movimento estava presente em vários setores da sociedade, dentre eles a família e a escola. Cuidar do corpo e da saúde era a orientação preconizada para educar a população brasileira.

Nesse contexto, havia a necessidade de robustecer as mulheres para que gerassem filhos fortes e saudáveis para a pátria em desenvolvimento, porém sem comprometer suas formas feminis, sua graça e beleza estética. Segundo Devide (2004), elas foram alvo do discurso eugênico. Esse cenário propiciou a inserção das mulheres no esporte nas primeiras décadas do século XX, apoiadas pelo Estado brasileiro e por intelectuais da época.

Apesar dos incentivos governamentais, essa prática ainda era cercada de preconceitos e proibições, pois havia um certo estigma sobre a aceitação das mulheres nesse território, 
considerado masculino e masculinizante. Dentre os esportes sugeridos para elas, a natação conquista lugar de destaque, sendo considerado um dos mais "adequados" por não alterar muito as formas femininas e promover a saúde da futura mãe. Além disso, Devide e Votre (2012) afirmam que havia um receio por parte das mulheres da elite de se tornarem vulgares.

A prática feminina dessa modalidade se difunde nas primeiras décadas do século XX chegando aos anos 1950 como um dos esportes prediletos para elas. Nesse período a mulher esportista estava em plena expansão. No entanto, havia a proibição legal por meio do DecretoLei no 3.199, de 1941 (BRASIL, 2017), que vetava às mulheres "[...] a prática de desportos incompatíveis com as condições de sua natureza". Esse decreto vigorou até 1975 e, segundo Mourão (2000), incorporou as representações sociais do feminino e seu papel reprodutor.

Semelhante a outras regiões do país, em Salvador a prática da natação feminina nos anos 1950 era uma realidade. Quanto aos espaços para a prática da natação até fins de 1950,haviam duas piscinas na cidade: ado Instituto Normal da Bahia, construída entre 1936 e 1939 (AZEVEDO, 2007), e a do Yacht Clube da Bahia, inaugurada em 1938 (MAIA, 1995). Conjecturamos que as poucas piscinas e um litoral de enseadas propícias para a prática da natação favoreceram a cultura de se nadar no mar. Angela Maria Carvalho ${ }^{3}$, primeira mulher a participar da travessia,em 1956, rememora:“[...] naquela época, todo mundo nadava no mar. Nadar de Ribeira a Plataforma ${ }^{4}$ era 0 treino da gente [...]".

Nesse cenário surge em 1955 a Travessia Baía de Todos os Santos - a Travessia Mar Grande-Salvador, como ficou conhecida. Considerada uma das mais antigas provas do gênero no Brasil, em A Tarde (MARCADA PARA DOMINGO A ELIMINATÓRIA DOS NADADORES, 1956, p. 5) e Diario de Noticias (TRAVESSIA MAR GRANDE-SALVADOR, 1956, p.6) era apontada como uma das mais longas e importantes do país. A Baía de Todos os Santos é 0 cenário com saída na praia do Duro, Ilha de Itaparica, e chegada na praia do Porto da Barra, Salvador.

A participação feminina inicia em 1956 com a presença de uma única nadadora. Com o título "Uma mulher na prova de natação Mar Grande-Salvador", a reportagem anunciava: "[...] a mulher bahiana estará representada na segunda Travessia Baía de Todos os Santos, através da mocidade e da beleza de Angela Maria" (UMA MULHER NA PROVA DE NATAÇÃO, 1956, p.2).Em 1957, participaram da competição: Marlene Gomes Nascimento (sem clube), Angela Maria (Esporte Clube Bahia), Marília Barreiros (Esporte Clube Vitória), e a paulista Egle Blanco (Internacional de Regatas de Santos) conforme A Tarde (FOI SENSACIONAL A TRAVESSIA DA BAÍA DE TODOS OS SANTOS, 1957, p. 9).

Nos anos 1950, a educação das mulheres preservava características feminis, dessa forma, termos como "mocidade e beleza", registrados nos jornais ao anunciarem a participação das mulheres na travessia, informam um "modo de ser" característico da mulher da década de 1950. O recato, a docilidade, a obediência aos pais, a preservação da virgindade, a valorização da "moça de família", o casamento por amor, a boa esposa, a divisão dos papéis masculinos e femininos representavam o universo das mulheres dessa época, portanto faziam parte da sua educação. Concomitantemente, elas agregavam novas conquistas e liberdades, como, por exemplo, praticar atividades físico-esportivas. 
Parte dessa realidade está na narrativa de Angela Carvalho quando rememora sua participação num evento esportivo ocorrido no Dique do Tororó, em Salvador, após sua participação na segunda Travessia Mar Grande-Salvador: "[...] no outro dia meu namorado foi na repartição de meu pai e pediu a minha mão em casamento, quando chegou de noite eu já estava noiva e não sabia, e aí me proibiu de nadar! Eu era rebelde mas não fui tanto! Aí parei de nadar". Esse depoimento revela uma educação familiar na qual, segundo Pinsky (2015), o homem tinha autoridade e poder sobre as mulheres. Para elas não havia possibilidade de contestação.

Mesmo com restrições, a participação da nadadora na travessia assumiu importância em relação ao seu comportamento e aos das nadadoras que, posteriormente, participaram da competição. Ao tensionar a educação à época, elas possibilitaram novas conquistas e superaram desafios, o que oportunizou uma postura mais segura, corajosa e ousada, tanto para elas quanto para as que as sucederam.

Os noticiários das primeiras participações das mulheres na Travessia Mar GrandeSalvador, nos anos de 1956 e 1957, apontam para um perfil de mulher típico do período. Referências à feminilidade, à beleza das formas e à classe eram utilizadas nas matérias produzidas pelos jornais. Expressões tais como: "belo sexo", "muita fibra" e, sobretudo, "classe", "mocidade e beleza", "corajosa e bela", "formosas e jovens atletas", retratam um modelo fortemente inculcado nas mulheres dos Anos Dourados ${ }^{5}$, o que sobrepuja a performance das nadadoras e, de certa maneira, diminui ou mesmo invisibiliza suas qualidades atléticas.

Essa invisibilidade é expressa também nos periódicos por meio dos poucos registros imagéticos das nadadoras nos diferentes momentos da competição. Nas imagens aparecem vestidas com uniformes ou traje social e em ambientes fora da competição. Em contraposição, os homens atletas eram registrados com imagens em trajes de banho em diversos momentos da prova.

Outro elemento importante da travessia na década de 1950 é o número reduzido de atletas mulheres quando comparado ao número de atletas homens. Na segunda edição da prova, em 1956, apenas uma participa. Em 1957, quatro mulheres, três baianas e uma paulista. Nesse ano a diferença entre a participação das mulheres (quatro) em relação aos homens (26) aponta para resistências sociais à época que nos remetem às questões de gênero. Ao se falar de gênero "[...] é preciso enfatizar que ele é muito mais que simples interações entre homens e mulheres. É preciso compreendê-lo como uma estrutura ampla, que engloba tanto a economia e o Estado quanto a família e a sexualidade" (SILVA,1998, p. 175). E acrescenta "0 gênero é uma estrutura complexa, para além das dicotomias sexuais (homem $\mathrm{x}$ mulher) e das especificidades da reprodução".

O apoio e incentivo social para a prática esportiva feminina ainda não era uma ação social cotidiana, mas restrita a certas famílias. Nas famílias das entrevistadas já havia uma cultura esportiva, com familiares envolvidos em diversas ações como atletas, treinadores ou dirigentes.

Ao se referir à representação social da sua participação na travessia para a época, Angela Carvalho conta: "Antigamente as mulheres eram muito donas de casa. As moças eram

5 Como ficaram conhecidas as mulheres da classe média dos anos de 1950, no Brasil, encarnavam um modelo de mulher com papéis sociais bem definidos. Ser mãe, dona de casa, esposa, feminina, graciosa, obediente, doce, pura e resignada tipificava as características da mulher ideal (PINSKY, 2015). 
criadas bordando, tocando piano [...]. Aí, o que é que acontece: eles achavam que uma mulher não podia fazer aquilo". Essa narrativa nos remete à compreensão de Pinsky (2013b) sobre a educação nessa época. Apesar dos avanços e incentivos para novas práticas, como o esporte, a educação das mulheres preserva e preservava hábitos, costumes, comportamentos, enfim, uma educação que a preparasse para desenvolver o papel social de dona de casa, mãe e esposa.

Mais de meio século após a primeira participação feminina na prova, constatamos que na 52ª edição da Travessia, em 2016, apenas 20 participantes são mulheres. Sued Marcus Nogueira Awad ${ }^{6}$, diretor da Federação Baiana de Desportos Aquáticos e árbitro internacional de maratonas aquáticas, comenta que: "Das cem vagas para a Travessia de 2016, trinta foram reservadas para as mulheres. Destas trinta, somente vinte foram preenchidas. A média de participação tem sido de 15 a 20 mulheres".

Ao analisarmos as informações do depoente, constatamos que a proporção homens/mulheres participantes evoluiu, em relação às duas primeiras competições, embora timidamente. Portanto, com relevante desproporção. Isso pode nos indicar uma permanência de resistências sociais e educacionais em relação à participação das mulheres em competições dessa natureza. Para Sued Awad: "A resolução em participar da prova decorre da saída das mulheres da condição de acompanhantes dos namorados e maridos para a de participantes". Essa situação nos remete ao início da participação de mulheres no esporte.

Desirée Dalia ${ }^{7}$, professora de Educação Física, nadadora e recordista feminina em número de participações na Travessia, reflete: "A gente não percebe, mas existem ainda resistências domésticas. É dos maridos. Está treinando demais! Tá abandonando os filhos!", conta ela se referindo aos discursos de alguns esposos das suas alunas. Além disso, acrescenta: "Muitas mulheres deixam de treinar com receio de prejudicar a educação dos filhos. A pressão de alguns maridos termina por fazê-las desistir".

A realidade posta por Desirée indica que permanecem certas representações sobre as mulheres. Pinsky (2013a) fala de papéis como o da mãe abnegada, que se coloca em segundo plano frente às necessidades da família. A permissão para usufruir do lazer, de cuidar de si mesma, de realizar projetos pessoais termina por ficar subordinada a papéis tradicionalmente esperados para elas.

Diferente da experiente Desirée, a estreante Fernanda Silva Scher ${ }^{8}$, que participou da sua primeira Travessia em 2016, comenta:

É muito difícil para uma mulher, nos dias atuais, se submeter a uma rotina para a preparação. A vida moderna, os inúmeros afazeres, a questão financeira e a falta de compartilhamento dos maridos são alguns dos motivos. A sociedade ainda não está organizada do ponto de vista da mulher.

Scott (2013, p. 38), no mesmo sentido, conclui que "[...] ainda temos uma estrada bem longa e difícil para que a divisão equitativa das responsabilidades e isonomia entre homens e mulheres entre nós brasileiros sejam alcançadas".

Ainda sobre resistências, a preocupação com a masculinização do corpo das mulheres se constitui em um fator impeditivo para a maior adesão ao esporte. Sobre isso, Angela Carvalho rememora: "O pessoal dizia que quem nadava, a mulher que nadava, ficava com

6 Sued Marcus Nogueira Awad. Entrevista maio 2016. 
muito músculo, com o ombro mais largo". Essa ideia expressa a preocupação com a perda da feminilidade da mulher, tão valorizada nos Anos Dourados.

Fernanda Scher atribui ao medo de desenvolver os ombros um dos motivos para que muitas mulheres não se submetam ao treinamento. Sobre isso comenta: "Algumas mulheres que conheço dizem: 'Não nade muito! Porque vai ficar com o ombro largo'”. Isso indica que a representação do corpo feminino, longe de ter sido característica de uma época, permanece.

A respeito da masculinização dos corpos, Goellner (2012) afirma que essa crença de que algumas modalidades esportivas masculinizam as mulheres deve ser analisada e discutida. Na natação, o estigma do ombro largo é exemplo disso. O padrão da mulher feminina, do "belo sexo", da graciosidade, termina por causar o afastamento de meninas e mulheres de algumas modalidades esportivas, ainda que o modelo feminino atual tenha se alterado um pouco para um modelo mais atlético.

Fica evidente que o avanço das mulheres no campo esportivo sofreu resistências sociais e impedimentos legais, o que postergou o seu acesso às práticas esportivas consideradas "nocivas" à sua "natureza" e, portanto, não adequadas à sua educação. Para Goellner (2005), a prática esportiva feminina causava temor porque desestabilizava o terreno masculino assentado no discurso biológico da inferioridade feminina. No entanto, as proibições e restrições não impediram que mulheres desconstruíssem certas teorias biológicas vigentes, demonstrando potencialidades e habilidades atléticas; se apropriando, pouco a pouco, do campo esportivo e o incorporando às suas vidas, na perspectiva do lazer, da saúde ou do rendimento.

\section{CONSIDERAÇÕES FINAIS}

Este artigo pretendeu discutir a educação de mulheres no esporte, com destaque para as representações e papéis sociais que lhes são tradicionalmente concedidos, a partir de uma pesquisa histórica sobre sua participação na Travessia Mar Grande-Salvador, Bahia, Brasil, prova de natação em mar aberto na Baía de Todos os Santos, nos anos 1956, 1957 e 2016. Por meio da História Oral e documental, considerados de forma individual e coletiva, porque feitos e/ou relatados por sujeitos históricos e sociais, pudemos constatar que, no esporte, a educação das mulheres segue padrões sociais normativos do ser homem e do ser mulher, definidos historicamente, o que dificulta a inserção feminina em diversas modalidades, entre elas nas competições de natação em mar aberto por $10 \mathrm{~km}$.

As mulheres que participaram deste estudo inscrevem-se em um extrato social de classe média escolarizada, com semelhança ao que ocorria nos primórdios das participações femininas na natação no Brasil.

Outra consideração refere-se à desproporção entre homens e mulheres na participação das edições pesquisadas da Travessia, que ainda hoje é relevante. Os depoimentos relacionados ao desequilíbrio na proporção homens/mulheres participantes da prova aludem como mais significativo um desejo de as mulheres se encaixarem em uma hegemonia por um "padrão de corpo feminino", um "corpo perfeito" que se distancia de um "corpo esportivo modelar", que pode levar a uma masculinização do corpo feminino e, consequentemente, a restrições sociais.

Há uma crença social de que certas modalidades esportivas, como a natação, por exemplo, masculinizam as mulheres. O estigma do "ombro largo" que acompanha a prática da natação deixa clara a permanência de uma representação de feminilidade que valoriza a 
delicadeza e a harmonia das formas. Apesar de Pinsky (2013b) sugerir que esse modelo se firma até o início de 1960, nesta pesquisa essa crença ainda é presente. As resistências sociais quanto à participação das mulheres em meados de 1950 e em 2016 persistem.

Nos anos 1950 a participação das mulheres no esporte de forma geral, e na travessia, em específico, seguia uma lógica de subserviência da mulher ao homem, a uma lógica do mando masculino. A educação das mulheres, à época, definia papéis sociais para elas tais como casar, ser dona de casa e mãe de família. E outras práticas eram recriminadas porque consideradas "ousadas", como as travessias a nado em mar aberto.

Apesar dos anos que separam as duas primeiras participações das mulheres na Travessia da sua $52^{\underline{a}}$ edição, constatamos algumas permanências e algumas mudanças. Das permanências destacamos a pressão que muitas mulheres sofrem de pais, namorados e companheiros em relação à postura e às ações definidas socialmente e cobradas cotidianamente para as mulheres, como representações que atribuem às mulheres a responsabilidade no cuidado com os filhos e as atividades domésticas. Permanece, em certa medida, um ideário de mulher abnegada e subserviente.

Para modificar esse cenário é preciso alterar a lógica educacional de formação humana, de homens e mulheres que se compreendam como parceiros, ambos com amplas possibilidades de existir e de realizar diversas atividades, seja no espaço doméstico, seja no espaço público. E no esporte essa questão não é diferente. Precisamos buscar ações educativas que promovam uma equanimidade entre os gêneros, o fim da divisão de papéis sociais entre mulheres e homens, no esporte e na vida.

A permanência de cobranças, limitações, preconceitos e resistências às mulheres no esporte, no caso, na natação em mar aberto, aqui representada pela Travessia Mar GrandeSalvador, aponta um paradigma de educação com papéis hierárquicos submissos para as mulheres e representações sociais do feminino que cerceia direitos e outras sociabilidades.

Porém, o protagonismo das mulheres que se lançaram e se lançam ao mar, a despeito das correntezas, contribuiu e concorre para romper velhos padrões, modificando lógicas de dominação machistas, de modo a ressignificar e ampliar os papéis sociais que historicamente foram atribuídos às mulheres no esporte e, quem sabe, construir relações mais igualitárias entre homens e mulheres, alterando lógicas e ampliando horizontes.

De forma pontual a Travessia Mar Grande-Salvador significou um avanço na educação e na vida das mulheres que participaram de suas edições, além de ser um marco na história da natação feminina na Bahia e no Brasil. Enfim, ao produzir outros sentidos para as mulheres no esporte, essas mulheres proporcionaram e proporcionam uma abertura de caminhos e produzem novas formas de encarar desafios. Assim, o "belo sexo" ousou na natação em mar aberto, no esporte e, certamente, em outros espaços da vida cotidiana, influenciando o social para, e quiçá, transformá-lo. 


\section{REFERÊNCIAS}

ALBERTI, Verena. Manual de história oral. 3. ed. Rio de Janeiro: Editora FGV, 2005.

AZEVEDO, Paulo Ormindo de.Alexander S. Buddeüs: a passagem do cometa pela Bahia. Vitruvius, fev. 2007. Disponível em: <http://www.vitruvius.com.br/revistas/read/ arquitextos/07.081/268>. Acesso em: 21 set. 2016.

BRASIL. Câmara dos Deputados. Decreto-lei no 3.199 de 14 de abril de 1951. Disponível em: <http://www2.camara.leg.br/legin/fed/declei/1940-1949/decreto-lei-3199-14-abril-1941-413238publicacaooriginal-1-pe.html .Acesso em: 10 maio 2017.

DELGADO, Lucilia de Ameida Neves. História oral: memória, tempo e identidades. Belo Horizonte: Autêntica, 2006.

DEVIDE, Fabiano Pries. A natação como elemento da cultura física feminina no início do século XX: construindo corpos saudáveis, belos e graciosos. Movimento, v.10, n.2, p. 125-144, maio/ ago, 2004.

DEVIDE, Fabiano Pries; VOTRE, Sebastião Josué. Primórdios da natação competitiva feminina: do "páreo elegância" aos Jogos Olímpicos de Los Angeles. Revista Brasileira de Ciências do Esporte, v.34, n.1, p. 217-233, jan./mar. 2012.

DEVIDE, Fabiano Pries. História das mulheres na natação brasileira no século XX: das adequações às resistências sociais. São Paulo: Hucitec, 2012.

FOI SENSACIONAL A TRAVESSIA DA BAÍA DE TODOS OS SANTOS. A Tarde. Salvador, 21 jan. 1957, v. 45, n. 14.978, p.9.

GOELLNER, Silvana Vilodre. Mulher e esporte no Brasil: entre incentivos e interdições elas fazem história. Pensar a Prática, v. 8, n. 1, p. 85-100, 2005.

GOELLNER. Silvana Vilodre. Mulheres e esportes: sobre conquistas e desafios. Revista do Observatório Brasil da Igualdade de Gênero, v.2, n. 4, dez.2012. Disponível em: <http://www. spm.gov.br/sobre/publicacoes/publicacoes/2012/revista-observatorio final_portugues.pdf>. Acesso em: 10 jan. 2017

GÓIS JUNIOR, Edvaldo; SIMÕES, José Luís. A história da educação física no Brasil. Recife: Ed. Universitária da UFPE, 2011.

HAHNER, June Edith. Honra e distinção das famílias. In: PINSKY, Carla Bassanezi; PEDRO, Joana Maria (Orgs.). Nova História das mulheres no Brasil. São Paulo: Contexto, 2013. p.43-64.

LOURO, Guacira Lopes. Gênero, sexualidade e educação: uma perspectiva pós-estruturalista. Petrópolis: Vozes, 1997.

LOURO, Guacira Lopes. Mulheres na Sala de Aula. In: PRIORE, Mary De; PINSKY, Carla Bassanezi(Coord.). História das mulheres no Brasil.10.ed. São Paulo: Contexto, 2015. p. 443 -481 .

MAIA, Adinoel Motta. late Clube da Bahia: 60 anos de história. Salvador: late Clube da Bahia, 1995. MARCADA PARA DOMINGO A ELIMINATÓRIA DOS NADADORES. A Tarde. Salvador, 10 jan. 1956, v. 44, n. 14.667, p. 5. 
MEIHY, José Carlos Sebe Bom. Manual de história oral. 5.ed. São Paulo: Loyola, 2005.

MIGUEL, Raquel de Barros; RIAL, Carmen. Programa de mulher. In: PINSKY, Carla Bassanezi; PEDRO, Joana Maria (Orgs.). Nova História das mulheres no Brasil. São Paulo: Contexto, 2013. p. $148-168$.

MOURÃO, Ludmila. Representação social da mulher brasileira nas atividades físico-desportivas: da segregação à democratização. Movimento, v. 6, n. 13, p. 5-18, 2000.

UMA MULHER NA PROVA DE NATAÇÃO. Mar Grande - Salvador. A Tarde. Salvador, 11 jan. 1956, v. 44, n. 14.668 , p. 2.

PINSKY, Carla Bassanezi. A Era dos Modelos Flexíveis. In: PINSKY, Carla Bassanezi; PEDRO, Joana Maria (Orgs.). Nova História das mulheres no Brasil. São Paulo: Contexto, 2013a.p. $513-544$.

PINSKY, Carla Bassanezi. A Era dos Modelos Rígidos. In: PINSKY, Carla Bassanezi; PEDRO, Joana Maria (Orgs.). Nova História das mulheres no Brasil. São Paulo: Contexto, 2013b. p. $469-512$.

PINSKY, Carla Bassanezi. Mulheres dos Anos Dourados. In: PRIORE, Mary Del; PINSKY, Carla Bassanezi (Coord.). História das mulheres no Brasil. 10.ed. São Paulo: Contexto, 2015. p. $607-639$.

ROMANELLI, Otaíza de Oliveira. História da educação no Brasil (1930/1975). 17.ed. Petrópolis: Vozes, 1995.

SCOTT, Ana Silvia. O caleidoscópio dos arranjos familiares. In: PINSKY, Carla Bassanezi; PEDRO, Joana Maria (Orgs.). Nova História das mulheres no Brasil. São Paulo: Contexto, 2013. p. $15-42$.

SILVA, Maria Cecília de Paula Silva. O esporte e a formação da mulher no início do século XX: significados históricos no espaço escolar. In: OLIVEIRA, Vitor Marinho de (Org.). História oral aplicada à educação física brasileira. Rio de Janeiro: Editoria Central da Universidade Gama Filho, 1998. p.169-204.

THOMPSON, Paul. A voz do passado: história oral. São Paulo: Paz e Terra, 1992.

TRAVESSIA MAR GRANDE-SALVADOR. Diario de Noticias. Salvador, 24 jan. 1956, v. 80, n.16.419, p.6.

VERÓN, Eliseo. A produção de sentidos. São Paulo: Cultrix: Editora da Universidade de São Paulo, 1980. 